\title{
Compact Size Triple Notched-bands UWB Antenna with Sharp Band-Rejection Characteristics at WiMAX and WLAN Bands
}

\author{
Mahmoud F. Habash ${ }^{1}$, Anour S. Tantawy ${ }^{1}$, Hany A. Atallah ${ }^{2 *}$, and Adel B. Abdel-Rahman ${ }^{2}$ \\ ${ }^{1}$ Telecom Egypt Company, Qena, Egypt \\ ${ }^{2}$ Electronics and Communications Engineering, Electrical Engineering, Faculty of Engineering, South Valley University, Qena \\ 83523, Egypt \\ mahmoud.haroun@te.eg, anwar.mostafa@te.eg, h.atallah@eng.svu.edu.eg*,adel.bedair@ejust.edu.eg
}

\begin{abstract}
In this paper, a compact triple band-notched ultrawideband (UWB) antenna with sharp band-elimination features and controlled notched bandwidths is proposed and discussed. The design is made up of a rectangular-shaped patch UWB planar monopole antenna with double collections of bandnotched configurations. The band-notched configurations are involved to produce the desired lower and upper stop bands with good frequency selectivity and suitable stop bandwidths. The first notch is realized by using a C-shaped slot etched in the radiating patch in order to eliminate the interference at the WiMAX $(3.4-3.8 \mathrm{GHz})$ applications. The second and the third notches are realized together by using a pair of U-shaped resonators that are located beside the feed line in both sides to eliminate the interference with the lower WLAN (5.15-5.35 GHz) and the higher WLAN $(5.725-5.825 \mathrm{GHz})$ bands. Additionally, the bandwidths of the lower and upper stop bands can be controlled separately by changing the parameters of the band-notched configurations. Furthermore, the suggested triple notched bands UWB antenna is optimized, fabricated, and measured for verification purposes. The measured results are close to the simulated ones.
\end{abstract}

\section{Introduction}

The Federal Communications Commission (FCC) authorizes the unlicensed use of ultrawideband (UWB) at the frequency range from 3.1 to $10.6 \mathrm{GHz}$ for commercial determinations [1]. UWB technology has appealed much more consideration for wireless communication uses [2, 3]. However, there are some other present narrowband communication applications that will cause unwanted interference with the UWB band, for example, the bands at the worldwide interoperability for microwave access (WiMAX) and the wireless local area network (WLAN). The UWB antenna with a sharp multiple band notched properties is effectively required for solving the problem of the unwanted interference. Recently, the UWB antennas with the elimination of single band $[4,5]$, the dual-band [6$8]$, the triple band $[9,10]$, multiband $[2,11]$, and tunable bands $[12,13]$ have been proposed and argued [4-13]. A numerous procedures and designs proposed in the literature including the usage of electromagnetic band gap (EBG) structures [14], defected ground structures (DGS) [15], Metamaterial-based antennas have been also used to provide notch for UWB antennas [16], and designing new slots in different shapes on the radiator or on the ground plane [17]. In this paper, a triple notched-bands UWB antenna is presented, fabricated, and discussed. The suggested approach is depending on using two collections of bandstop configurations to create the desired three rejection bands. The first one consists of a C-shaped slot etched in the patch to reject the (WiMAX) band at (3.4-3.8 GHz). The second one consists of two pairs of U-shape resonators located around the feed line on both sides to reject the lower (5.15$5.35 \mathrm{GHz}$ ) and higher (5.725-5.825 GHz) (WLAN) bands. The triple-notched bands can be created and realized by controlling the parameters of the U-shaped resonators and the C-shaped slot. Section 2 investigates and discusses in details the structure of the triple band-rejected antenna. The studies are carried out using computer simulations and the simulated results are confirmed using fabrications and measurements. Furthermore, the measured and simulated results are showed, compared, and discussed in section 3 . The measured $\mathrm{S}_{11}$ parameter is in a good agreement with the simulated one.

\section{Antenna Design and Studies}

The antenna and its dimensions are shown in Fig. 1 (a) and Fig.1 (b) which have an exact size of $47 \mathrm{~mm} \times 38$ $\mathrm{mm} \times 0.813 \mathrm{~mm}$. A printed UWB rectangular monopole antenna which is firstly designed with its original dimensions on the bottom side that is obtained in [18]. The used substrate is Rogers $4003 \mathrm{C}$ and it has a dielectric constant equals $\varepsilon_{r}=3.3$, a height of $0.813 \mathrm{~mm}$, and a loss tangent $\delta=0.00027$. For impedance bandwidth improvement the radiator patch is stepped for the best matching of the microstrip feed line and the patch [19] as shown in Fig. 1(a). The effect of radiator dimensions has been discussed in [18]. The band-notched configurations are involved to produce the wanted lower and upper stop bands with good frequency selectivity and suitable stop 
bandwidths to eliminate the interference with WiMAX band at $(3.4-3.8 \mathrm{GHz})$, lower WLAN band at $(5.15-5.35 \mathrm{GHz})$, and higher WLAN band at $(5.725-5.825 \mathrm{GHz})$ as shown in Fig. 2. The presented antenna is optimized through simulations using a commercial 3D full-wave analysis software package computer simulation technology (CST).

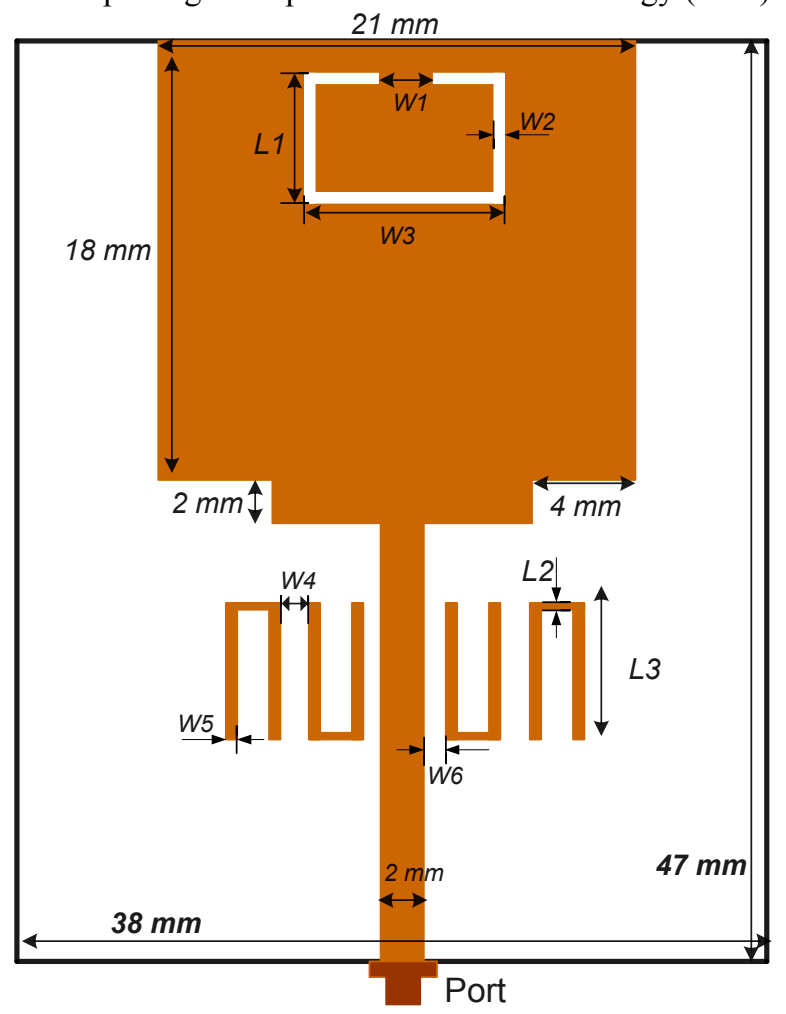

(a)

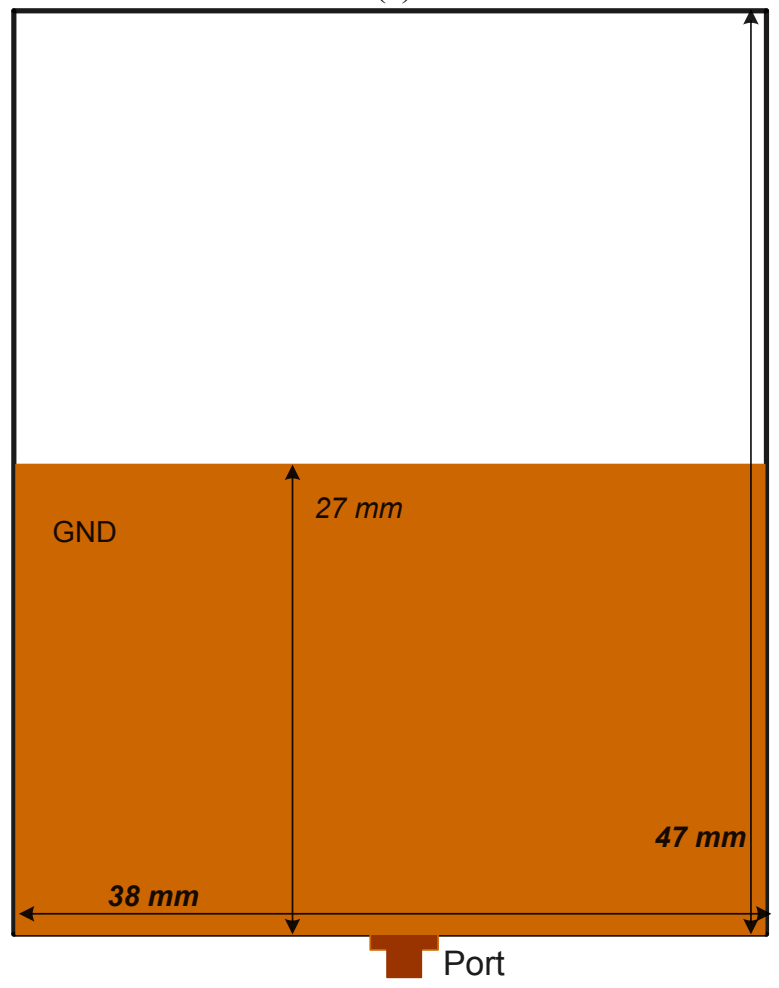

(b)

Figure 1: Layout of the proposed design: (a) Top view. (b) Bottom view.

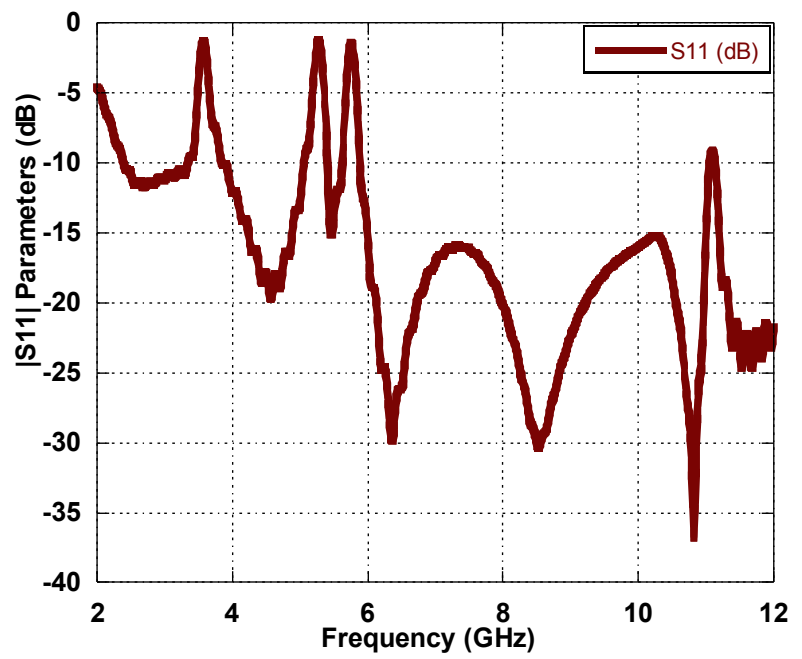

Figure 2: Simulated results of the UWB antenna with triple notches.

The first notch is achieved by etching a C-shaped slot inside the radiator patch to reject the WiMAX band at (3.4$3.8 \mathrm{GHz}$ ). Consequently, the achieved rejection level is high because the slot is etched inside the radiator and is placed near the maximum field position. The bandwidth can be controlled by changing the position of the slot on the radiator patch. The resonance frequency of the band which will be removed can be controlled by varying and optimizing the length $(L 1)$ of the C-shaped slot as shown in Fig. 3. After the optimization has been done, the optimum dimensions lengths of this slot are given in Table 1.

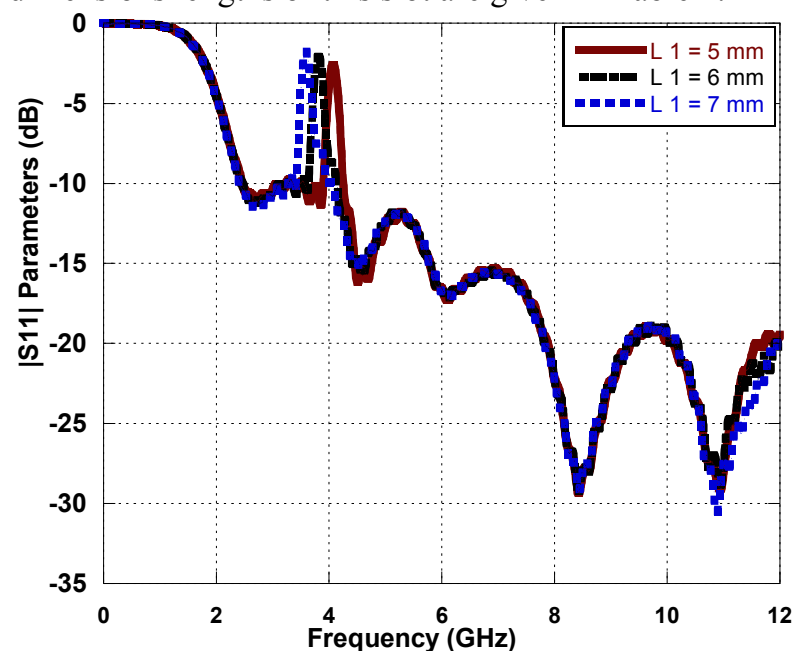

Figure 3: The effect of changing the length of the $\mathrm{C}$-shaped slot $(L 1)$ on the $\mathrm{S}_{11}$ parameters.

Table 1: Dimensions of the triple band notched configuration.

\begin{tabular}{|l|l|l|l|}
\hline Parameter & $\begin{array}{c}\text { Dimension } \\
(\mathrm{mm})\end{array}$ & Parameter & \multicolumn{1}{|c|}{$\begin{array}{c}\text { Dimension } \\
(\mathrm{mm})\end{array}$} \\
\hline$W 1$ & 2 & W6 & 0.35 \\
\hline$W 2$ & 0.4 & L1 & 5 \\
\hline$W 3$ & 12 & L2 & 0.6 \\
\hline$W 4$ & 1 & L3 & 8.7 \\
\hline$W 5$ & 1 & & \\
\hline
\end{tabular}


The second and the third notches are obtained together by coupling collections of two pairs of U-shape resonators arranged in a symmetry configuration around the feed line in both sides as shown in Fig. 1(a) to reject the lower WLAN band at $(5.15-5.35 \mathrm{GHz})$ and the higher WLAN band at $(5.725-5.825 \mathrm{GHz})$ as shown in Fig. 2. The resonance frequencies of those bands can be controlled by varying and optimizing the length L3 of the U-shaped resonators as shown in Fig. 4. While the bandwidth can be controlled by changing the position of the U-shaped resonators. Figure 4 indicates that any change in the dimensions of the U-shaped resonators does not have any significant influence on the first notch at the WiMAX band. At the end of the optimization process, the optimum dimensions of these resonators and all notched configurations are given in Table 1.

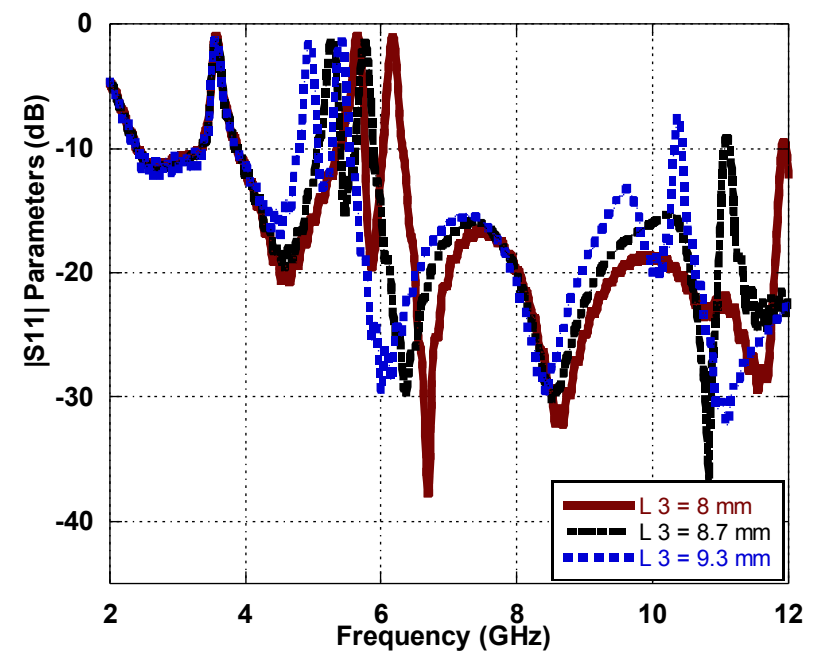

Figure 4: The effect of changing the length of the Ushaped (L3) on the $\mathrm{S}_{11}$ parameters.

\section{Experimental Verifications and Results}

The proposed triple notched bands antenna is fabricated and measured for confirmation. The photograph of the fabricated prototype is shown in Fig. 5. Figure 6 shows a good agreement between the measured and the simulated return loss $\left(\mathrm{S}_{11}\right)$ of the proposed antenna. Consequently, these results approve that the antenna is suitable for UWB applications. Moreover, the measured elimination levels at the notches are quite high as can be noticed in Fig. 6.

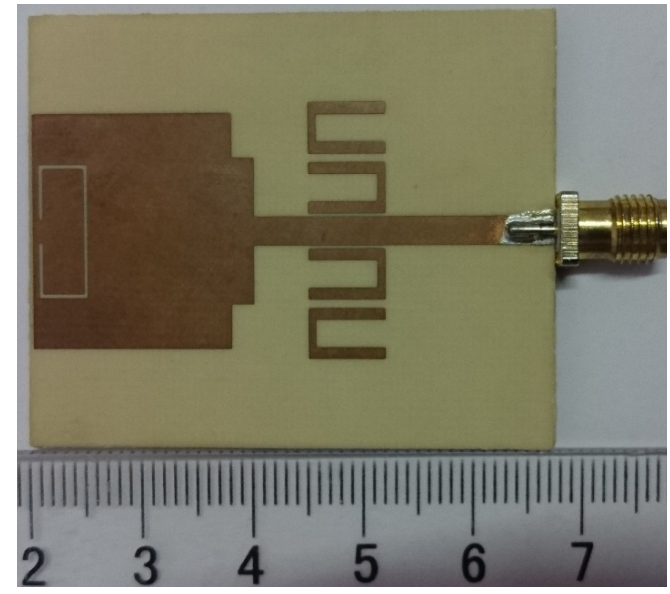

(a)

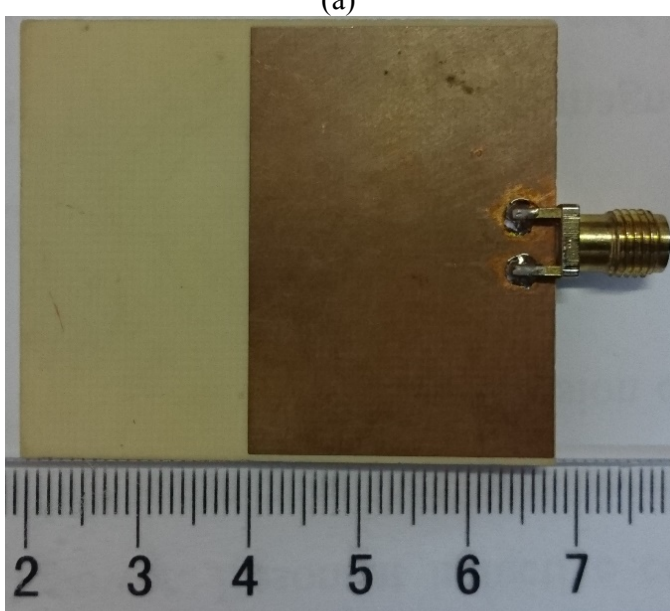

(b)

Figure 5: Photographs of the fabricated triple bandnotched antenna: (a) Top view. (b) Bottom view.

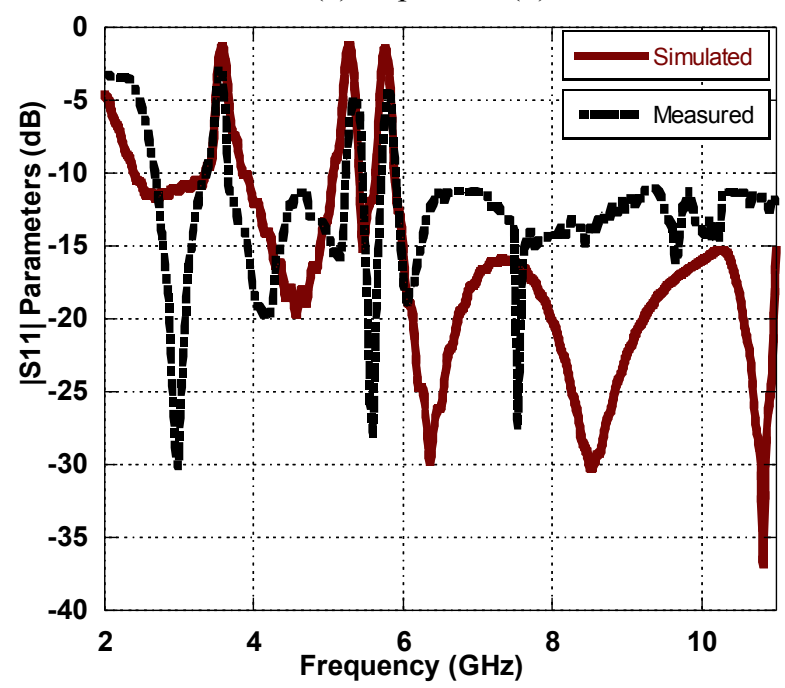

Figure 6. Comparisons of the simulated and the measured S11 of the proposed design.

Figure 7 indicates that the simulated peak realized gain of the suggested UWB antenna with triple notched bands is nearly constant and uniform at the passband at the frequency range from $2.7 \mathrm{GHz}$ to $11 \mathrm{GHz}$ except at the notched bands at $(3.4-3.8 \mathrm{GHz}),(5.15-5.35 \mathrm{GHz})$, and 
(5.725-5.825 GHz) which have substantial decreases in the realized gain which nearly more than $4 \mathrm{~dB}$. Furthermore, the simulated total efficiency is presented in Fig. 7 for more confirmation. The patterns on the $\mathrm{H}(\mathrm{x}-\mathrm{z})$ plane and $\mathrm{E}(\mathrm{y}-\mathrm{z})$ plane at the selected frequencies $(3.1,5,7.5,10.5 \mathrm{GHz})$ are plotted in Fig. 8. The simulated E-plane and H-plane polarization levels are steady from the specified plots so the antenna exhibits a stable Omnidirectional radiation pattern at the passband and confirmed from the chosen working frequencies. Moreover, the radiation patterns do not show any noteworthy alterations. To conclude, the radiation patterns are stable over the operating frequency range except at the intended notches and the antenna acts like a monopole.

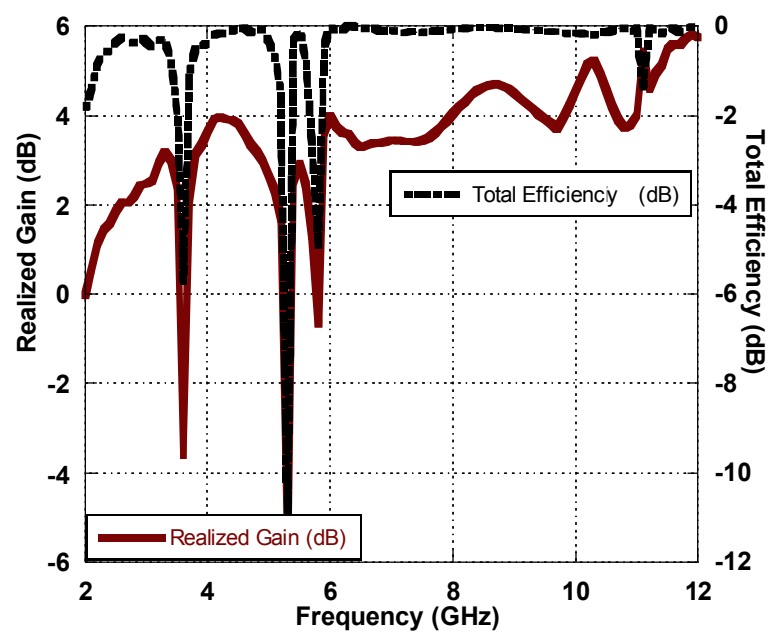

Figure 7: The realized gain of the proposed design.

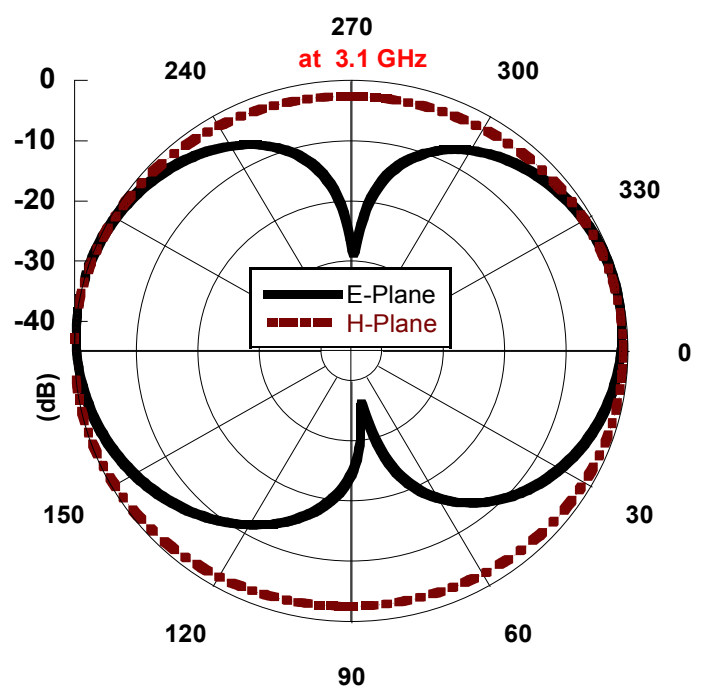

(a) At $3.1 \mathrm{GHz}$

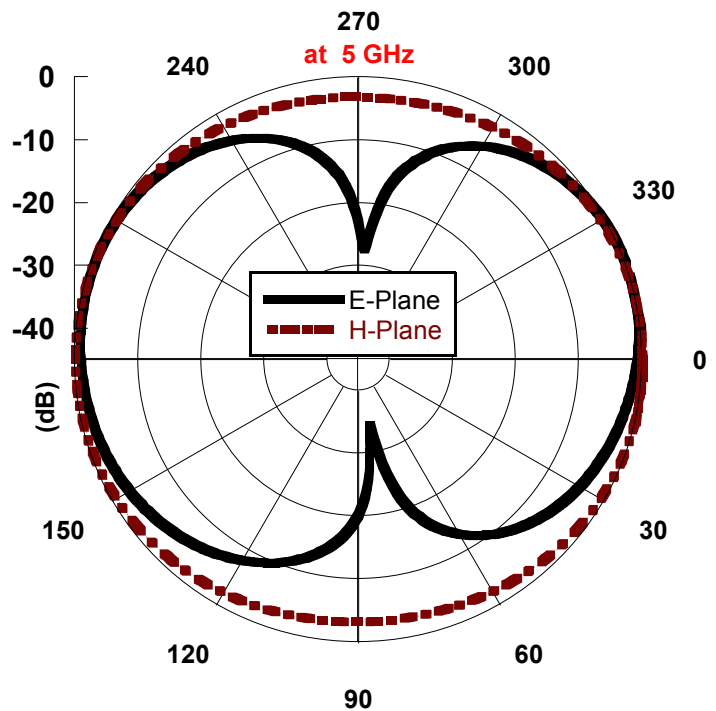

(b) At $5 \mathrm{GHz}$

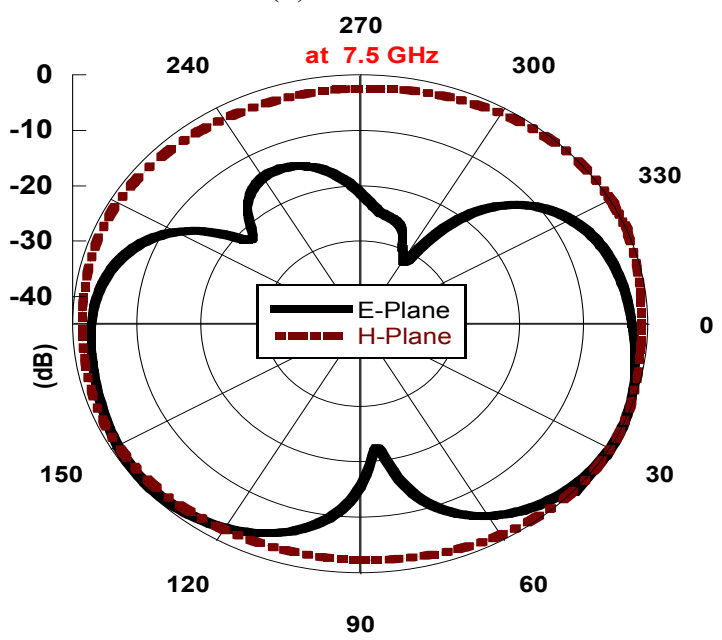

(c) At $7.5 \mathrm{GHz}$

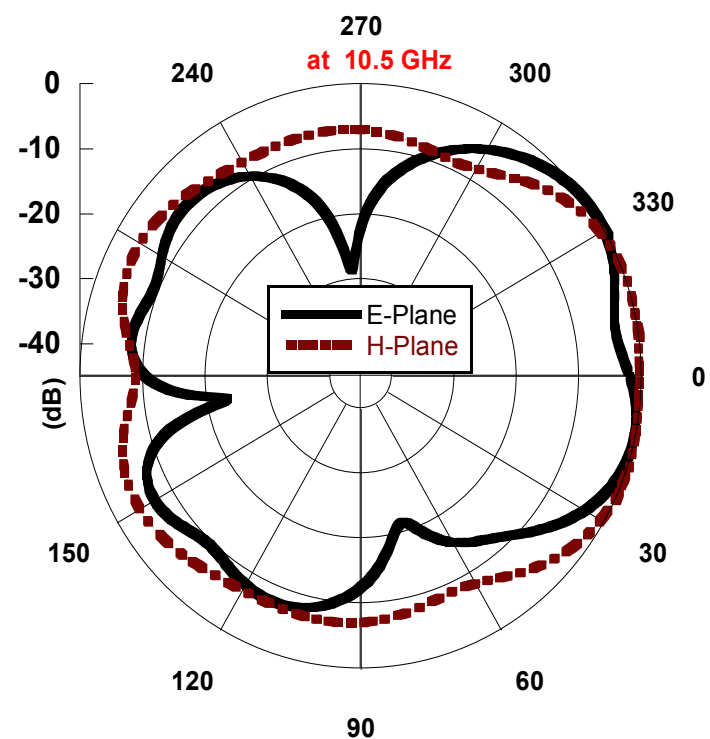

(d) At $10.5 \mathrm{GHz}$

Figure 8: The Normalized radiation patterns (E- and Hplanes). (a) At $3.1 \mathrm{GHz}$, (b) At $5 \mathrm{GHz}$, (c) At $7.5 \mathrm{GHz}$, and (d) At $10.5 \mathrm{GHz}$. 


\section{Conclusion}

In this paper, a UWB antenna with three notched bands is presented and discussed. The design is optimized by computer simulation program and then fabricated for validation. The suggested antenna has multi advantages such small size of $38 \mathrm{~mm} \times 47 \mathrm{~mm} \times 0.813 \mathrm{~mm}$. The antenna achieves three sharp notched bands at WiMAX, lower, and higher WLAN to avoid the interference with these current wireless systems. Besides, the achieved gain over all the working bandwidth is acceptable except at the eliminated bands. The antenna achieves stable Omnidirectional radiation patterns over the working frequencies. Finally, the antenna is fabricated and measured. The obtained results demonstrate good covenant with the simulated ones. With these features, the suggested antenna is suitable for UWB applications.

\section{References}

[1] Federal Communication Commission, "Revision of part 15 of the commission's rules regarding ultra wideband transmission systems," Tech. Rep. ETDocket 98-153, FCC02-48, Apr. 2002.

[2] Hany A. Atallah, Adel B. Abdel-Rahman, Kuniaki Yoshitomi, and Ramesh K. Pokharel, "CPW feed UWB filter-antenna with sharp and high rejection multiple notched bands using stub loaded meander line resonator," AEU-International Journal of Electronics and Communications, vol. 83, pp. 22-31, 2017.

[3] B. Satyanarayana and S. Mulgi, "Design of planar band-notched monopole antenna for $2.4 \mathrm{GHz}$ WLAN and UWB applications," Microwave and Optical Technology Letters, vol. 57, no. 11, pp. 2496-2501, 2015.

[4] S. M. Abbas, Y. Ranga, Anand K. Verma, and Karu P. Esselle, "A simple ultra wideband printed monopole antenna with high band rejection and wide radiation patterns," IEEE Transactions on Antennas and Propagation, vol. 62, no. 9, pp. 4816-4820, Sept. 2014.

[5] W.-J. Lui, C.-H. Cheng, and H.-B. Zhu, "Improved frequency notched ultra wideband slot antenna using square ring resonator," IEEE Transactions on Antennas and Propagation, vol. 55, no. 9, pp 2445-2450, Sep 2007.

[6] Q. X. Chu and Y. Y. Yang, "A compact ultrawideband antenna with $3.4 / 5.5 \mathrm{GHz}$ dual band-notched characteristics," IEEE Transactions on Antennas and Propagation, vol. 56, pp. 3637-3644, Dec. 2008.

[7] Hany A. Atallah, Adel B. Abdel-Rahman, Kuniaki Yoshitomi, and Ramesh K. Pokharel, "Design of dual band-notched CPW-fed UWB planar monopole antenna using microstrip resonators," Progress in Electromagnetics Research Letters (PIER L), vol. 59, pp. 51-56, March 2016.

[8] K. S. Ryu and A. A. Kishk, "UWB antenna with single or dual band notches for lower WLAN band and upper WLAN band," IEEE Transactions on Antennas and Propagation, vol. 57, pp. 3942-3950, Dec. 2009.
[9] W. T. Li, X. W. Shi, and Y. Q. Hei, "Novel planar UWB monopole antenna with triple band-notched characteristics," IEEE Antennas Wireless Propagation Letters, vol. 8, pp. 1094-1098, 2009.

[10] C. C. Lin, P. Lin, and R. W. Ziolkowski, "Single, dual, and tri-band notched ultra wideband (UWB) antennas using capacitively loaded loop (CLL) resonators," IEEE Transactions on Antennas and Propagation, vol. 60, pp. 102-109, Jan. 2012.

[11] Y. Zhang, W. Hong, C. Yu, Z.-Q. Kuai, Y.-D. Don, and J.-Y. Zhou, "Planar ultrawideband antennas with multiple notched bands based on etched slots on the patch and/or split ring resonators on the feed line," IEEE Transactions on Antennas and Propagation, vol. 56, no. 9, pp. 3063-3068, Oct. 2008.

[12] Hany A. Atallah, Adel B. Abdel-Rahman, Kuniaki Yoshitomi, and Ramesh K. Pokharel, "Tunable bandnotched CPW-Fed UWB monopole antenna using capacitively loaded microstrip resonator for cognitive radio applications," Progress in Electromagnetics Research C (PIER C), vol. 62, pp. 109-117, January 2016.

[13] Hany A. Atallah, Adel B. Abdel-Rahman, Kuniaki Yoshitomi, and Ramesh K. Pokharel, "Reconfigurable band-notched slot antenna using short circuited quarter wavelength microstrip resonators," Progress in Electromagnetic Research C (PIER C), vol. 68, pp. 119-127, September 2016.

[14] L. Kurra, M. P. Abegaonkar, A. Basu, and S. K. Koul, "Switchable and tunable notch in ultra-wideband filter using electromagnetic bandgap structure," IEEE Microwave and Wireless Components Letters, vol. 24, no. 12, pp. 839-841, 2014.

[15] A. Nouri and G. R. Dadashzadeh, "A compact UWB band-notched printed monopole antenna with defected ground structure," IEEE Antennas and Wireless Propagation Letters, vol. 10, pp. 1178-1184, 2011.

[16] S. Kahng, E. C. Shin, G. H. Jang, J. Anguera, J. H. Ju, and J. Choi, "A UWB antenna combined with the CRLH metamaterial UWB bandpass filter having the bandstop at the $5 \mathrm{GHz}$-band WLAN," IEEE Antennas and Propagation Society International Symposium, Charleston, SC, 2009, pp. 1-4.

[17] D. T. Nguyen, D. H. Lee, and H. C. Park, "Very compact printed triple band-notched UWB antenna with quarter-wavelength slots," IEEE Antennas and Wireless Propagation Letters, vol. 11, pp. 411-414, 2012.

[18] K. P. Ray, "Design aspects of printed monopole antennas for ultra-wide band applications," International Journal of Antennas and Propagation, vol. 2008, 2008. doi:10.1155/2008/713858.

[19] Z. N. Low, J. H. Cheong, and C. L. Law, "Low-cost PCB antenna for UWB applications", IEEE Antennas and Wireless Propagation Letters, vol. 4, 2005. 